\title{
MICROSTRUCTURAL AND MECHANICAL PROPERTY CHARACTERIZATION OF SUPERPLASTICALLY FORMED INCONEL alloy 718SPF
}

\author{
Gaylord D. Smith and Daniel H. Yates \\ Inco Alloys International, Inc. \\ P. O. Box 1958 \\ Huntington, WV 25720 \\ Peter N. Comley \\ Murdock, Inc. \\ 15800 S. Avalon Boulevard \\ Compton, CA 90220 \\ Yan Ma and Terence G. Langdon \\ Department of Materials Science and Mechanical Engineering \\ University of Southern California \\ Los Angeles, CA 90089
}

\begin{abstract}
Superplastic forming (SPF) of aluminum- and titanium-based alloys has become a significant manufacturing method for aerospace engine and fuselage components. Largely overlooked by design engineers is the applicability of fine-grained INCONEL ${ }^{\circledR}$ alloy 718 SPF* ${ }^{*}$ to this process. This paper seeks to show the compatibility of this alloy to current SPF practice and equipment. Extensive processing parameters are presented based on laboratory data as well as post SPF tensile properties taken from material processed on commercial SPF equipment.
\end{abstract}

INCONEL alloy $718 \mathrm{SPF}$ can be superplastically formed at $954^{\circ} \mathrm{C}\left(1750^{\circ} \mathrm{F}\right)$ using flow stresses generally less than $72 \mathrm{MPa}(10.4 \mathrm{psi}$ ) at an initial strain rate of $1.3 \times 10-3 \mathrm{~s}-1$ and $<28 \mathrm{MPa}$ (4 psi) at $1.3 \times 10-4 \mathrm{~s}-1$. The elongation to failure increases markedly with decreasing strain rate, exceeding $350 \%$ at an initial strain rate of $1.3 \times 10-3 s-1,450 \%$ at $1.3 \times 10-4 s-1$ and $750 \%$ at 3.3 $x 10-5 s-1$. Laboratory data are used to calculate " $m$ " values (a measure of strain rate sensitivity) which increase from 0.28 at an initial strain rate of $1.3 \times 10-3 s-1$, to 0.45 at $1.3 \times 10-4 s-1$ and to 0.83 at $3.3 \times 10-5 \mathrm{~s}-1$.

The original tensile properties and grain size are compared to the post SPF-processed material for several values of total strain. For material SPF-processed through engineering strains of less than approximately $200 \%$, original properties persist. Achievement under these processing conditions of nominal aged tensile properties is similarly demonstrated.

Metallography is used to measure the percentage area of cavitation as a function of total strain and at failure for several strain rates. Under similar conditions, the average roundness coefficient (a measure of cavity growth by diffusion) is also computed for various strain rates. At an initial strain rate of $10-2 \mathrm{~s}-1$, the area of cavitation at failure is $<0.01 \%$ but increases with decreasing strain rate becoming $2.8 \%$ at $370 \%$ engineering strain and a strain rate of $1.3 \times 10-3 \mathrm{~s}-1$. The average roundness coefficient increases from 0.47 to 0.63 for the conditions described above.

(8*INCONEL and 718SPF are trademarks of the Inco family of companies. 


\section{Introduction}

There is a market need for complex shaped parts for commercial and military aircraft applications requiring high nickel alloys to withstand a combination of high temperature, hot gas corrosion and high strength. Conventional methods of fabricating these components requires extensive welding and fabrication methods resulting in higher than desired costs and excessive parts inventories. Superplastic forming, now highly sophisticated and used extensively for producing titanium and aluminum alloy aircraft parts, would be an ideal solution for producing nickel alloy components as well. However, for this to occur, a minimum level of technology must exist for an alloy which both meets the technical requirements of the end-use and is amenable to the SPF practices and equipment now in commercial use. This paper seeks to show the applicability of INCONEL alloy 718 SPF to this manufacturing method by describing the SPF characteristics of this alloy and the subsequent properties and microstructure of the finished part. The merits of INCONEL alloy 718 for commercial and military aircraft airframe and engine components have been long established and are widely known.

\section{Materials and Procedures}

Two heats of INCONEL alloy 718SPF were selected for this study. The composition of each heat is presented in Table 1. Tensile properties and grain size are given in Table 2 . These heats were produced by vacuum melting followed by electroslag remelting. The material was then hot worked using conventional practice. However, the cold working procedure was altered to assure the production of an ultrafine grain size.

Heat HT3463EK was evaluated for superplastic forming characteristics by $Y$. Ma and T. G. Langdon at the University of Southern California, Los Angeles, CA (1). Heat HT4262EK was superplastically formed on conventional SPF equipment by P. Comley of Murdock, Inc., Compton, $\mathrm{CA}$ at $954^{\circ} \mathrm{C}\left(1,750^{\circ} \mathrm{F}\right)$ using an argon gas pressure of $2.1 \mathrm{MPa}$ (300 psi) and a time of approximately $4 \mathrm{~h}$. The SPF part was evaluated for tensile properties life and microstructure (grain size and area of cavitation) at various locations in the component.

\section{Superplastic Forming Characteristics of INCONEL alloy 718SPF}

$954^{\circ} \mathrm{C}\left(1,750^{\circ} \mathrm{F}\right)$ was chosen as the aim temperature for characterization of the SPF parameters of INCONEL alloy 718SPF. (2) The grain size stability of INCONEL alloy 718 SPF during the time for typical SPF of a conventional component should be excellent at $954^{\circ} \mathrm{C}\left(1,750^{\circ} \mathrm{F}\right)$ as exemplified by the grain size data shown in Figure 1.

Table 1. Composition of INCONEL alloy 718SPF Heats Studied (Wt \%)

\begin{tabular}{|c|c|c|c|c|c|c|c|c|c|c|}
\hline Heat Number & $C$ & Mn & $s$ & $\mathrm{Fe}$ & $\mathrm{Ni}$ & $\mathrm{Cr}$ & $\mathrm{Al}$ & $\mathrm{Ti}$ & $\mathrm{MO}$ & $\mathrm{Nb}$ \\
\hline HT3463EK & 0.02 & 0.08 & 0.001 & 18.04 & 53.52 & 18.51 & 0.47 & 1.04 & 3.04 & 5.01 \\
\hline HT4262EK & 0.03 & 0.08 & 0.001 & 17.97 & 53.47 & 18.47 & 0.52 & 1.04 & 2.88 & 5.11 \\
\hline
\end{tabular}


Table 2. Mechanical Properties of Mill Annealed INCONEL alloy 718SPF

\begin{tabular}{|c|c|c|c|c|}
\hline & \multicolumn{4}{|c|}{ Room Temperature Tensile Properties } \\
\hline & \multicolumn{2}{|c|}{$\begin{array}{c}\text { Heat HT3463EK } \\
0.51 \mathrm{~mm}(0.02 \mathrm{in}) \text { gauge }\end{array}$} & \multicolumn{2}{|c|}{$\begin{array}{c}\text { Heat HT4262EK } \\
1.22 \mathrm{~mm}(0.048 \mathrm{in}) \text { gauge }\end{array}$} \\
\hline \multicolumn{5}{|l|}{ Mill Annealed* } \\
\hline $0.2 \%$ Y.S., MPa (ksi) & \multicolumn{2}{|c|}{$852(124)$} & \multicolumn{2}{|c|}{$815(118)$} \\
\hline U.T.S., MPa (ksi) & \multicolumn{2}{|c|}{$1,121(163)$} & \multicolumn{2}{|c|}{$1,114(162)$} \\
\hline Elongation, \% & \multicolumn{2}{|c|}{29.0} & \multicolumn{2}{|c|}{33.0} \\
\hline Hardness, Rc & \multicolumn{2}{|c|}{25} & \multicolumn{2}{|c|}{32} \\
\hline Grain Size ASTM \# & \multicolumn{2}{|c|}{13} & \multicolumn{2}{|c|}{12} \\
\hline \multicolumn{5}{|l|}{ Aged** } \\
\hline $0.2 \%$ Y.S., MPa (ksi) & \multicolumn{2}{|c|}{$1,461(212)$} & \multicolumn{2}{|c|}{$1,323(192)$} \\
\hline U.T.S., MPa (ksi) & \multicolumn{2}{|c|}{$1,586(230)$} & \multicolumn{2}{|c|}{$1,519(220)$} \\
\hline Elongation, \% & \multicolumn{2}{|c|}{14.0} & \multicolumn{2}{|c|}{19.0} \\
\hline Hardness, Rc & \multicolumn{2}{|c|}{44} & \multicolumn{2}{|c|}{46} \\
\hline Aged** & \multicolumn{4}{|c|}{$649^{\circ} \mathrm{C}\left(1200^{\circ} \mathrm{F}\right)$ Tensile Properties } \\
\hline $0.2 \%$ Y.S., MPa (ksi) & \multicolumn{2}{|c|}{$1,116(162)$} & \multicolumn{2}{|c|}{$1,105(160)$} \\
\hline U.T.S., (MPa (ksi) & \multicolumn{2}{|c|}{$1,201(174)$} & \multicolumn{2}{|c|}{$1,244(180)$} \\
\hline Elongation, \% & \multicolumn{2}{|c|}{22.0} & \multicolumn{2}{|c|}{21.0} \\
\hline Aged** & \multicolumn{4}{|c|}{$649^{\circ} \mathrm{C}\left(1200^{\circ} \mathrm{F}\right)$ Stress Rupture Properties } \\
\hline & Life $h$ & Elong. \% & Life $h$ & Elong. \% \\
\hline Stress, $793 \mathrm{MPa}$ (115 ksi) & 12.2 & 9.8 & - & - \\
\hline Stress, $724 \mathrm{MPa}$ (105 ksi) & - & - & 57.7 & 12.5 \\
\hline
\end{tabular}

${ }^{\star}$ Continuous Process Anneal: $927^{\circ} \mathrm{C}\left(1700^{\circ} \mathrm{F}\right) / 4.57 \mathrm{M}(15 \mathrm{ft})$ per min.

**Aging Condition: $954^{\circ} \mathrm{C}\left(1750^{\circ} \mathrm{F}\right) / 1 \mathrm{~h} / \mathrm{AC}$ plus $719^{\circ} \mathrm{C}\left(1325^{\circ} \mathrm{F}\right) / 8 \mathrm{~h} / \mathrm{FC}$ at $56^{\circ} \mathrm{C}\left(100^{\circ} \mathrm{F}\right) / \mathrm{h}$ to $621^{\circ} \mathrm{C}\left(1150^{\circ} \mathrm{F}\right)$ plus $621^{\circ} \mathrm{C}\left(1150^{\circ} \mathrm{F}\right) / 8 \mathrm{~h} / \mathrm{AC}$.

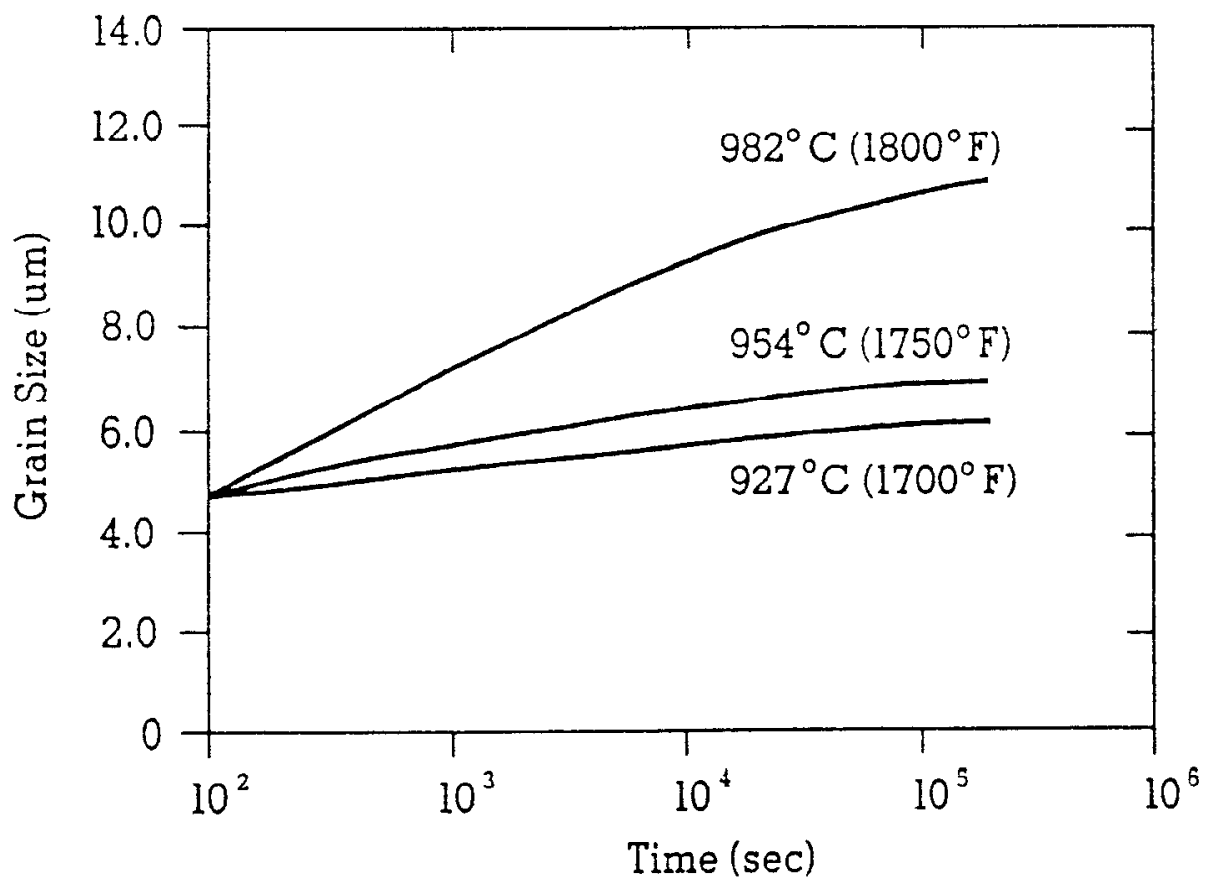

Figure 1. Plot of grain growth versus time at $927^{\circ} \mathrm{C}\left(1700^{\circ} \mathrm{F}\right), 954^{\circ} \mathrm{C}\left(1750^{\circ} \mathrm{F}\right)$ and $982^{\circ} \mathrm{C}$ $\left(1800^{\circ} \mathrm{F}\right)$ for INCONEL alloy $718 \mathrm{SPF}$. 
To conduct the SPF process parameter evaluation, ten specimens were machined from $1.22 \mathrm{~mm}$ (0.048 in) sheet of INCONEL alloy 718 SPF and tested at $954^{\circ} \mathrm{C}\left(1,750^{\circ} \mathrm{F}\right)$ to failure at varying strain rates from $1.33 \times 10-2 s-1$ to $1.33 \times 10-5 s-1$. The test results are presented in tabular form in Table 3 and graphically in Figure 2. A plot of engineering strain (total elongation) versus the initial strain rate is presented in Figure 3. Engineering strain increased from $150 \%$ at an initial strain rate of $1.3 \times 10-2 \mathrm{~s}-1$ to $760 \%$ at $3.3 \times 10-5 \mathrm{~s}-1$. For the typical SPF strain rates of $10-3$ to $10-4 s-1$, the available engineering strains are approximately $280 \%$ at the faster strain rate to $480 \%$ at the slower strain rate.

Table 3. The SPF Characteristics of Strain and Strain Rate at Maximum Stress and Elongation at Failure for 10 Initial Strain Rates for INCONEL alloy 718 SPF at $954^{\circ} \mathrm{C}$ $\left(1750^{\circ} \mathrm{F}\right)$

\begin{tabular}{|c|c|c|c|}
\hline Specimen & Initial Strain Rate, $\mathbf{s}^{-1}$ & Elongation to Failure, \% & Max. Stress, MPa (ksi) \\
\hline 1 & $1.33 \times 10^{-2}$ & 150 & $154.4(22.4)$ \\
\hline 2 & $6.67 \times 10^{-3}$ & 194 & $119.3(17.3)$ \\
\hline 3 & $3.33 \times 10^{-3}$ & 222 & $100.7(14.6)$ \\
\hline 4 & $1.33 \times 10^{-3}$ & 269 & $71.7(10.4)$ \\
\hline 5 & $6.67 \times 10^{-4}$ & 312 & $57.0(8.27)$ \\
\hline 6 & $3.33 \times 10^{-4}$ & 406 & $43.4(6.29)$ \\
\hline 7 & $1.33 \times 10^{-4}$ & 444 & $26.3(3.81)$ \\
\hline 8 & $6.67 \times 10^{-5}$ & 538 & $16.5(2.40)$ \\
\hline 9 & $3.33 \times 10^{-5}$ & 763 & $14.3(2.08)$ \\
\hline 10 & $1.33 \times 10^{-5}$ & 212 & $4.9(0.71)$ \\
\hline Specimen & Strain at Max Stress, \% & \multicolumn{2}{|c|}{ Strain Rate at Max Stress, $\mathbf{s}^{-1}$} \\
\hline 1 & 19.2 & \multicolumn{2}{|c|}{$1.12 \times 10^{-2}$} \\
\hline 2 & 19.2 & \multicolumn{2}{|c|}{$5.60 \times 10^{-3}$} \\
\hline 3 & 19.6 & \multicolumn{2}{|c|}{$2.78 \times 10^{-3}$} \\
\hline 4 & 85.1 & \multicolumn{2}{|c|}{$7.19 \times 10^{-4}$} \\
\hline 5 & 58.6 & \multicolumn{2}{|c|}{$4.21 \times 10^{-4}$} \\
\hline 6 & 109.0 & \multicolumn{2}{|c|}{$1.59 \times 10^{-4}$} \\
\hline 7 & 88.4 & \multicolumn{2}{|c|}{$7.06 \times 10^{-5}$} \\
\hline 8 & 146.0 & \multicolumn{2}{|c|}{$2.71 \times 10^{-5}$} \\
\hline 9 & 120.0 & \multicolumn{2}{|c|}{$1.51 \times 10^{-5}$} \\
\hline 10 & 137.0 & \multicolumn{2}{|c|}{$5.60 \times 10^{-6}$} \\
\hline
\end{tabular}




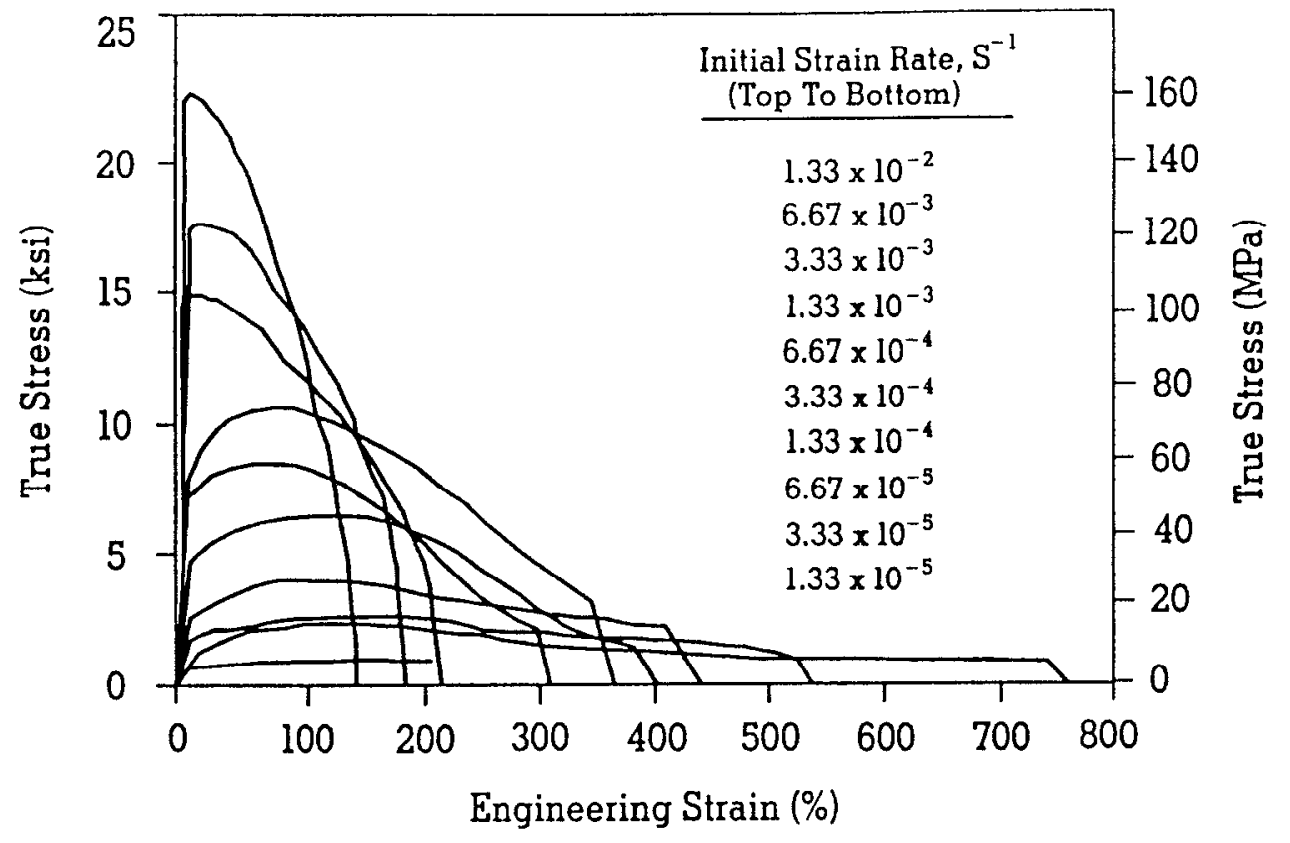

Figure 2. Plot of true stress versus engineering strain for 10 strain rates at $954^{\circ} \mathrm{C}$ $\left(1750^{\circ} \mathrm{F}\right)$, for INCONEL alloy 718 SPF, Heat HT3463EK.

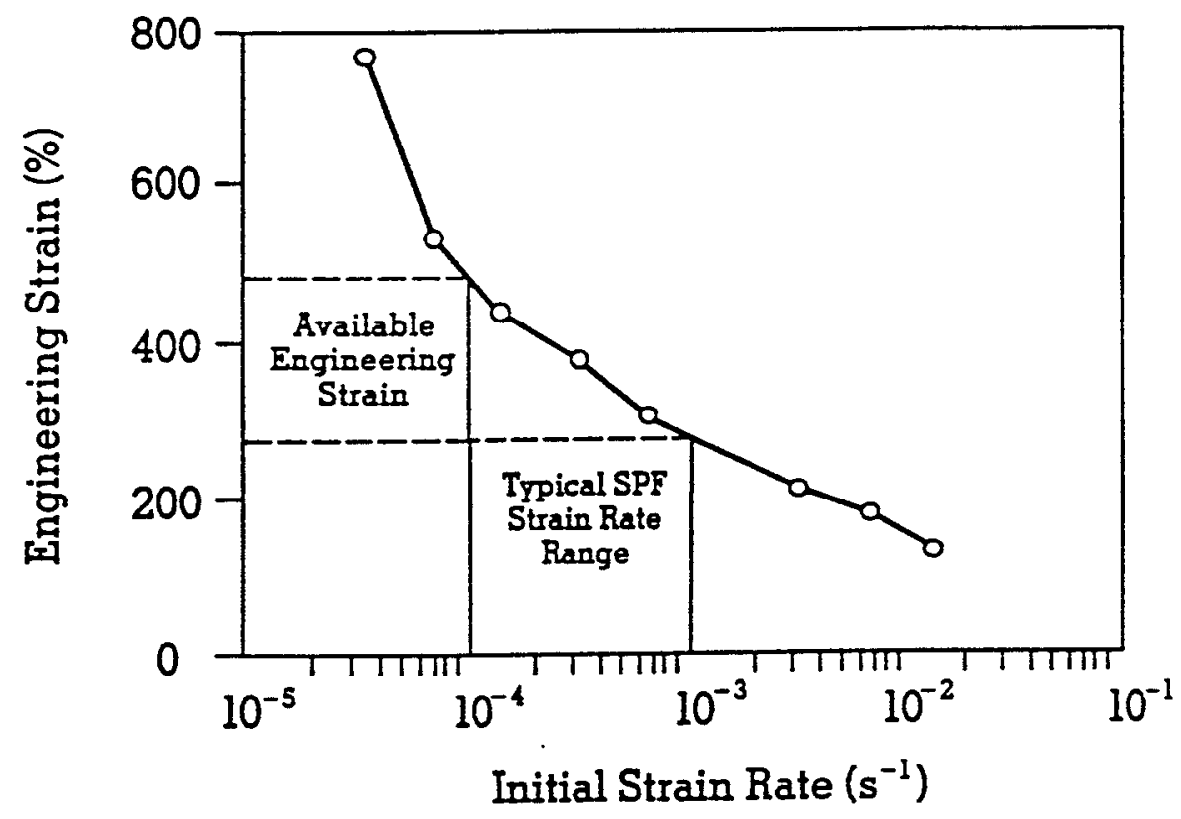

Figure 3. Engineering strain versus strain rate at $954^{\circ} \mathrm{C}\left(1750^{\circ} \mathrm{F}\right)$ for INCONEL alloy 718SPF, Heat HT3463EK. For typical SPF strain rates, the available engineering strain is highlighted.

A plot of the true strain rate at maximum stress versus the true stress at maximum stress is presented in Figure 4. This plot defines the maximum stresses that must be generated during SPF in order to deform INCONEL alloy 718SPF at the conventional strain rates of 10-3 to 10-4 $\mathrm{s}-1$. The necessary stress range is from nearly 27.6 to $82.7 \mathrm{MPa}$ (4 to $12 \mathrm{ksi}$ ). Also shown in 
Figure 4 is the changing value of $\mathrm{n}$ at different strain rates as determined by Equation 1 :

$$
\text { where } \dot{\epsilon}=\text { true strain rate, } \quad \dot{\sigma}=\kappa \sigma^{n}=\text { true stress }, \quad \kappa=\text { constant }
$$

The value of $n$ is the slope of $\log \dot{\epsilon}$ vs. $\log \sigma$ and is typically between 1 and 2.5 in the region of most practical SPF interest.(4)

True Stress $(\mathrm{MPa})$

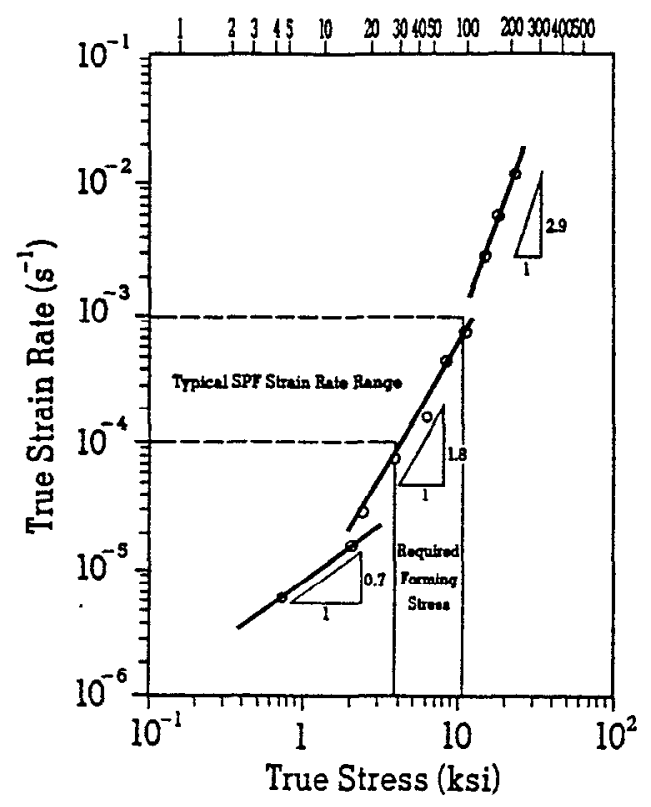

Figure 4. Plot of true rate vs. true stress (both at maximum stress) for INCONEL alloy 718SPF, Heat HT3463EK. For typical SPF strain rates, the required forming stress range is highlighted.

The measure of strain rate sensitivity, $m$, is calculated from the data of Table 3 and plotted in Figure 5. The $m$ value of INCONEL alloy 718 SPF does not reach 0.4 until the initial strain rate is reduced to $10^{-4} s^{-1}$ suggesting that INCONEL alloy 718 SPF is more precisely defined as a near-SPF alloy for the typical SPF conditions employed in industry today.

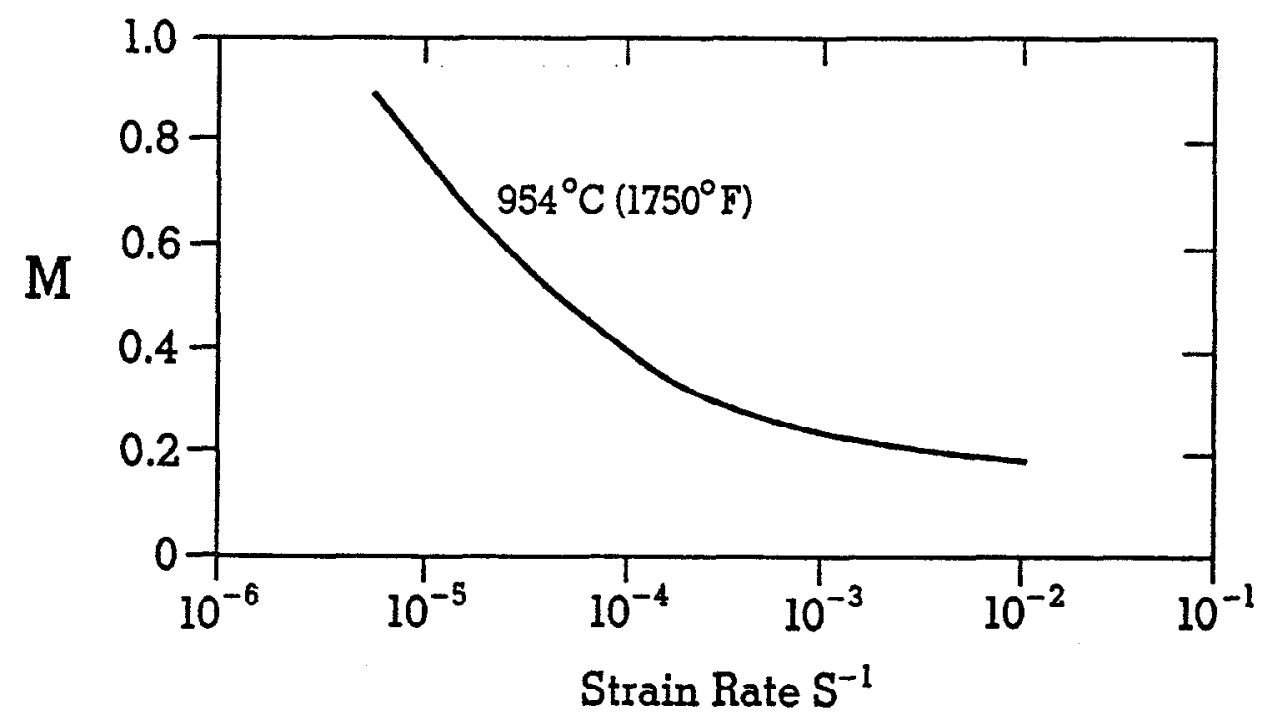

Figure 5. Plot of $m$ values, a measure of strain rate sensitivity versus strain rate at $954^{\circ} \mathrm{C}\left(1750^{\circ} \mathrm{F}\right)$ for INCONEL alloy $718 \mathrm{SPF}$. 


\section{Tensile Properties of Superplastically Formed INCONEL alloy 718SPF}

The heats of INCONEL alloy 718SPF used in this study were evaluated prior to initiating the SPF study for their tensile and stress rupture properties. See Table 2. Both heats meet the room temperature and $649^{\circ} \mathrm{C}\left(1,200^{\circ} \mathrm{F}\right)$ strength and ductility requirements of ASM 5596G as mill annealed and as aged.

Table 4 compares the mill annealed properties of INCONEL alloy 718SPF with that of superplastically formed material with reductions in gauge of $13 \%, 19 \%$ and $33 \%$. It is noted that under these conditions the alloy exceeds the annealed property maximum requirements of AMS $5596 \mathrm{G}$ due to the ultrafine grain size of the material. While grain size remains constant, increased deformation during SPF results in reduced hardness, tensile strength and elongation.

Table 4. Effect of SPF* on Room Temperature Tensile Properties of INCONEL alloy 718 SPF $1.22 \mathrm{~mm}$ (0.048 in.) Gauge Sheet

\begin{tabular}{|l|c|c|c|c|}
\hline \multirow{2}{*}{} & & \multicolumn{3}{|c|}{$\begin{array}{c}\text { Room Temperature Tensile Properties as } \\
\text { Function of Percent Reduction in Gauge }\end{array}$} \\
\cline { 2 - 5 } & Mill Annealed** & $13 \%$ & $19 \%$ & $33 \%$ \\
\hline \hline $0.2 \%$ Y.S ., MPa (ksi) & $\mathbf{8 1 5 ( 1 1 8 )}$ & $750(109)$ & $773(112)$ & $700(102)$ \\
\hline U.T.S., MPa (ksi) & $1,114(162)$ & $1,108(161)$ & $1,102(160)$ & $1,003(146)$ \\
\hline Elongation, \% & 33.0 & 22.0 & 22.0 & 14.0 \\
\hline Hardness, Rc & 32 & 29 & 27 & Rb 99 \\
\hline Grain Size ASTM No. & 12 & 12 & 12 & 12 \\
\hline
\end{tabular}

*SPF Conditions: $954^{\circ} \mathrm{C}\left(1750^{\circ} \mathrm{F}\right) / 2.06 \mathrm{MPa}(0.3 \mathrm{ksi})$

${ }^{* *}$ Continuous Process Anneal: $927^{\circ} \mathrm{C}\left(1700^{\circ} \mathrm{F}\right) / 4.57 \mathrm{M}(15 \mathrm{ft}) / \mathrm{min}$.

Table 5 shows the criticality of time $(0,0.33$ and $1.0 \mathrm{~h})$ at $954^{\circ} \mathrm{C}\left(1,700^{\circ} \mathrm{F}\right)$ on restoring aged room temperature tensile ductility (the minimum elongation of AMS $5596 \mathrm{G}$ is $12 \%$ ). Tensile properties and hardness are satisfactory as are tensile properties at $649^{\circ} \mathrm{C}\left(1,200^{\circ} \mathrm{F}\right)$ for the times evaluated. Because of the fine grain size of the post SPF material, it is not possible to achieve stress rupture properties of ASM 5596G without incorporating a grain growth annealing step prior to the aging heat treatment.

Table 5. Effect of Time at An Annealing Temperature of $954^{\circ} \mathrm{C}\left(1750^{\circ} \mathrm{F}\right)$ Prior to Aging* after SPF to $33 \%$ Reduction in Gauge

\begin{tabular}{|c|c|c|c|c|}
\hline & \multicolumn{4}{|c|}{ Room Temperature Tensile Properties } \\
\hline & $0.0 \mathrm{~h}$ & $0.33 \mathrm{~h}$ & $1.0 \mathrm{~h}$ & AMS 5596G** \\
\hline $\begin{array}{l}0.2 \% \text { Y.S., MPa } \\
\text { (ksi) }\end{array}$ & $989(143)$ & $1,140(165)$ & $1,193(173)$ & $1,034(150)$ \\
\hline U.T.S., MPa (ksi) & $1,171(170)$ & $1,325(192)$ & $1,372(199)$ & $1,241(180)$ \\
\hline Elongation, \% & 6.0 & 9.0 & 16.0 & 12.0 \\
\hline \multirow[t]{3}{*}{ Hardness, Rc } & 41 & 44 & 44 & 36 \\
\hline & \multicolumn{4}{|c|}{$649^{\circ} \mathrm{C}\left(1200^{\circ} \mathrm{F}\right)$ Tensile Properties } \\
\hline & $0.0 \mathrm{~h}$ & $0.33 \mathrm{~h}$ & $1.0 \mathrm{~h}$ & AMS 5596G** \\
\hline 0.2 Y.S., MPa (ksi) & $855(124)$ & $1,055(153)$ & $1,001(145)$ & $827(120)$ \\
\hline U.T.S., MPa (ksi) & $1,007(146)$ & $1,120(162)$ & $1,155(168)$ & $1,000(145)$ \\
\hline Elongation, \% & 26.0 & 16.0 & 20.0 & 5.0 \\
\hline
\end{tabular}

${ }^{\star}$ Aging Conditions: $719^{\circ} \mathrm{C}\left(1325^{\circ} \mathrm{F}\right) / 8 \mathrm{~h} / \mathrm{FC}$ at $56^{\circ} \mathrm{C}\left(100^{\circ} \mathrm{F}\right) / \mathrm{h}$ to $621^{\circ} \mathrm{C}\left(1,150^{\circ} \mathrm{F}\right)+621^{\circ} \mathrm{C}\left(1,150^{\circ} \mathrm{F}\right) / 8 \mathrm{~h} / \mathrm{AC}$

$\star \star$ Minimum Properties 


\section{Cavitation}

The propensity of INCONEL alloy 718 SPF to form pores during superplastically forming (cavitation) was measured (using an image analysis software package) by metallographic examination of the tensile specimens tested to fracture at varying initial strain rates at $954^{\circ} \mathrm{C}$ $\left(1,750^{\circ} \mathrm{F}\right)$ as exemplified in Table 6 . This alloy is subject to cavitation during SPF with the degree of cavitation increasing with decreasing initial strain rate. At an initial strain rate of $10-2 s-1$, the area of cavitation, as measured near the fracture tip, is less than $0.01 \%$ for a tensile elongation of $150 \%$. However, the degree of cavitation increases at a strain rate of $10-3 \mathrm{~s}-1$ to $2.0 \%$ (369\% elongation); becoming $10.3 \%$ at a strain rate of $10-5 s-1$ (538\% elongation). Table 6 shows that as the strain rate is decreased, the average cavity size and roundness coefficient increases. The average roundness coefficient is an indication of the degree of diffusion associated with cavity growth. A roundness coefficient of one indicates a perfect circular shape while a smaller value of the roundness coefficient relates more to cavity elongation. The increase in roundness coefficient at the strain rate of $10-3 \mathrm{~s}-1$ or less suggests that cavity growth by diffusion is becoming increasingly significant for decreasing strain rates (longer times at temperature).

Table 6. The Effect of Strain Rate at $954^{\circ} \mathrm{C}\left(1750^{\circ} \mathrm{F}\right)$ on The Size and Area of Cavitation of INCONEL alloy 718SPF The Average Roundness Coefficient of The Cavities Is Also Presented

\begin{tabular}{|l|c|c|c|}
\hline Strain Rate, $\mathrm{s}^{-1}$ & $1.3 \times 10^{-2}$ & $1.3 \times 10^{-3}$ & $6.7 \times 10^{-5}$ \\
\hline Total Elongation ${ }^{1}, \%$ & 150.0 & 369.0 & 538.0 \\
\hline Cavitatlon Area $^{2} \%$ & $<0.01$ & 2.60 & 10.60 \\
\hline Avg. Cavity Area, um ${ }^{2}$ & 5.20 & 145.0 & 580.0 \\
\hline Avg. Roundness Coefficient ${ }^{3}$ & 0.47 & 0.63 & 0.63 \\
\hline
\end{tabular}

'Specimen tested to fracture.

${ }^{2}$ Based on a measured area of $0.83 \mathrm{~mm}^{2}$ near the fracture tip.

${ }^{3}$ Defined as $(4 \pi \text { area)/perimeter })^{2}$ where a value of 1.0 represents a perfect circle and values less than 1.0 represent deviation from a circle.

Because SPF components are normally produced at strain rates of $10-3 s^{-1}$ to $10-4 s-1$ with actual total elongations of less than $200 \%$, four INCONEL alloy 718 SPF specimens were evaluated at $954^{\circ} \mathrm{C}\left(1,750^{\circ} \mathrm{F}\right)$ for strains of $86 \%$ and $194 \%$ at an initial strain rate of $10-3 \mathrm{~s}-1$ and for strains of $73 \%$ and $132 \%$ at an initial strain rate of $10-4 s-1$. The area of cavitation was measured metallographically using an area of $0.83 \mathrm{~mm}^{2}(0.0012 \mathrm{in} 2)$ from the gauge length. The results are presented in Table 7 and are combined with the results of Table 6 in Figure 6 . The data show that increasing elongation and decreasing strain rate, increase the area of cavitation. However, at total elongations of less than $200 \%$ at either a strain rate of $10-3$ or $10-4 s-1$, the area of cavitation is less than $0.5 \%$ and can be held below $0.1 \%$ for elongations of less than $100 \%$ at a strain rate of 10-3 s-1. Typical cavity size, as shown in Table 7, is again larger for the slower strain rate and greater total elongation. Cavitation tends to nucleate and grow around inclusions present in the alloy. Analysis of the number of cavities of a given size as a function of total strain shows a significant increase in the number of cavities within the smallest size range examined ( 0 to $2 \mu \mathrm{m} 2$ ) as the elongation increases, supporting the concept that cavities are continuously being nucleated throughout the test. Thus, the extent and distribution of inclusions becomes an important issue in superplastic forming of INCONEL alloy 718SPF. 
Table 7. The Effect of Strain Rate and Total Strain at $954^{\circ} \mathrm{C}\left(1750^{\circ} \mathrm{F}\right)$ on the Size and Area of Cavitation of INCONEL alloy 718SPF

\begin{tabular}{|l|c|c|c|c|}
\hline Initial Strain Rate, $\mathrm{s}^{-1}$ & $1.3 \times 10^{-3}$ & $1.3 \times 10^{-4}$ & $1.3 \times 10^{-3}$ & $1.3 \times 10^{-4}$ \\
\hline Total Strain, \% & 86.0 & 73.0 & 194.0 & 132.0 \\
\hline Cavitation Area, \% & 0.04 & 0.18 & 0.45 & 0.34 \\
\hline Avg. Cavity Size, um ${ }^{2}$ & 2.40 & 8.90 & 10.50 & 11.20 \\
\hline
\end{tabular}

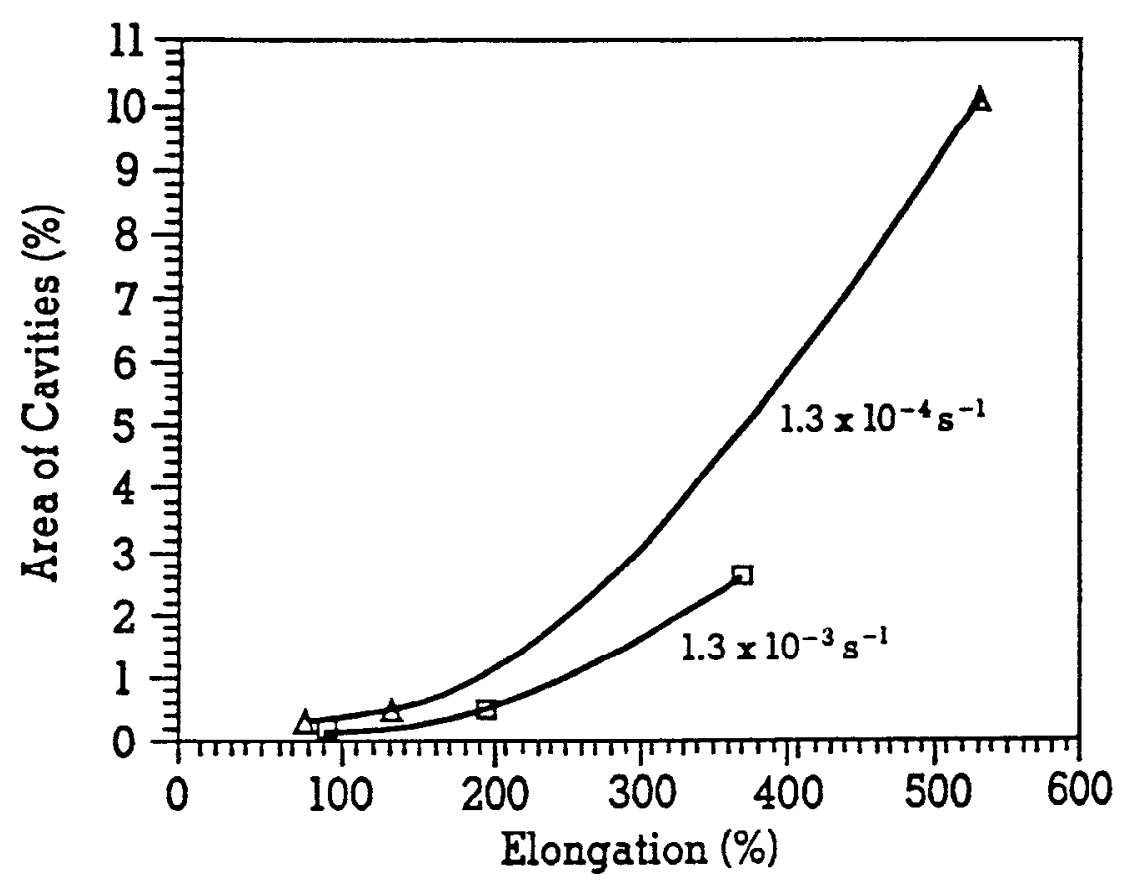

Figure 6. Plot of Percent Area of Cavitation Versus Total Elongation for Two Typical Strain Rates at $954^{\circ} \mathrm{C}\left(1750^{\circ} \mathrm{F}\right.$ for INCONEL alloy 718 SPF.

\section{Summary}

The aim of this paper is to show the applicability of INCONEL alloy 718SPF to current superplastic forming practice and equipment; to describe the processing parameters and to define the properties and microstructure of superplastically formed material. Based on this effort, a number of conclusions can be drawn:

1. INCONEL alloy 718 SPF can be produced with an ASTM grain size of \#10 or smaller and, subsequently, superplastically formed at $954^{\circ} \mathrm{C}\left(1750^{\circ} \mathrm{F}\right)$ using argon gas pressures of 2.1 MPa (300 psi).

2. For INCONEL alloy 718 SPF, the elongation to failure increases markedly with decreasing strain rate, exceeding $350 \%$ at an initial strain rate of $1.3 \times 10-3 s-1,450 \%$ at $1.3 \times 10-4 s-1$ and $750 \%$ at $3.3 \times 10-5 s^{-1}$.

3. For INCONEL alloy $718 \mathrm{SPF}$, the maximum true stress decreases with decreasing strain rate becoming less than $71.7 \mathrm{MPa}(10.4 \mathrm{psi})$ at an initial strain rate of $1.3 \times 10-3 \mathrm{~s}-1$ and less than $27.6 \mathrm{MPa}(4 \mathrm{psi})$ at $1.3 \times 10^{-4} \mathrm{~s}-1$. 
4. INCONEL alloy 718 SPF retains its original tensile properties after superplastic forming, at least, through engineering strains approximating $200 \%$.

5. AMS aged tensile properties are achieved through standard aging heat treatments.

6. The development of cavities at tensile failure is insignificant at a strain rate of $10-2 \mathrm{~s}-1$ (less than $0.01 \%$ by area) but becomes increasingly important as the strain rate decreases.

\section{References}

1. Y. Ma and T. G. Langdon, Private Communication, "Observations of Cavitation in Deformed INCONEL alloy 718", University of Southern California, February 1992.

2. M. W. Mahoney, "Superplastic Properties of INCONEL alloy 718," in Proceedings of the International Symposium on the Metallurgy and Applications of INCONEL alloy 718, June, 1989, Pittsburgh, PA, published by ASM.

3. T. G. Langdon, "Experimental Observations in Superplasticity," in Proceedings of Symposium on Superplastic Forming of Structural Alloys, June 1982, San Diego, CA, published by AIME.

4. R. C. Gifkins, "Mechanisms of Superplasticity." in Proceedings of Symposium on Superplastic Forming of Structural Alloys, June 1982, San Diego, CA, published by AIME. 